$$
\text { Mary Ann Liebert, Inc. puldishers }
$$

\title{
Expert Panel on Understanding Cannabis: Medicine, Society, Government
}

\author{
Moderator: Kyle Kazan ${ }^{1, \dagger}$ \\ Participants: Daniele Piomelli, ${ }^{2, *}$ Dana Rohrabacher, ${ }^{3}$ and Lori Ajax ${ }^{4}$
}

\begin{abstract}
On May 5, 2017, the Department of Anatomy and Neurobiology of the University of California Irvine convened an expert panel to discuss issues related to cannabis at the interface between medical science, society and government. The expert panel included Dr. Daniele Piomelli, U.S. Representative Dana Rohrabacher, Lori Ajax, and was moderated by Kyle Kazan.
\end{abstract}

Keywords: cannabis; cannabis legalization; marijuana regulation; medical marijuana

On May 5, 2017, the Department of Anatomy and Neurobiology of the University of California Irvine convened an expert panel to discuss issues related to cannabis at the interface between medical science, society, and government. The three invited speakers-Dr. Daniele Piomelli (University of California, Irvine), U.S. Representative Dana Rohrabacher (California's 48th District), and Lori Ajax (Bureau of Medical Cannabis Regulation California Department of Consumer Affairs)-briefly introduced each one of the topics to an audience of more than 200 people, and a lively discussion ensued. What follows are excerpts from the discussion.

Kyle Kazan: I have some questions for each of the three speakers. I will start with Dana. Many people in the cannabis business are wondering-and this is what I get asked most often-about Jeff Sessions. What do we think Mr. Sessions might do?

U.S. Representative Dana Rohrabacher: Jeff Sessions is a very good friend of mine. I have known him for 30 years. In fact, more than that. I met him when I was still a teenager and he was a teenager, and we were involved in conservative organizations. And every one of the conservative organizations that we were a part of stressed the constitutional government, including the 10th Amendment to the Constitution, which leaves things like this up to the states. And I have reminded him of that many times.

So let me just note, he is an honest man and a person who has a good heart. And just like many people who want to help you along by telling you what to do with your personal life, they are very well motivated in that they really have good hearts. They think they are helping you out. And Jeff came up in the 60s and saw people who were, you know, getting really wild, and that has impacted his vision of what it is going to be like [with legal cannabis].

So it is difficult to tell him that, yes, normal peoplepeople such as veterans and senior citizens and many other people, not just young people wanting to get wildneed to have the freedom to use cannabis. And that should be up to the state government and the people therein.

Quite frankly, if I was [on this panel] not as a federal representative, I would think I would not want as much

\footnotetext{
${ }^{1}$ AP Investment Fund.

${ }^{2}$ Department of Anatomy and Neurobiology, School of Medicine, University of California, Irvine, Irvine, California.

${ }^{3}$ U.S. Representative, California's 48th District, Washington, District of Columbia/Huntington Beach, California.

${ }^{4}$ Bureau of Medical Cannabis Regulation, California Department of Consumer Affairs.

†roviding real estate acquisition and private debt servicing to cannabis-related ventures.
}

*Address correspondence to: Daniele Piomelli, PhD, Department of Anatomy and Neurobiology, School of Medicine, University of California, Irvine, Irvine, CA 92697-1275, E-mail: piomelli@uci.edu

(c) Kyle Kazan et al. 2017; Published by Mary Ann Liebert, Inc. This is an Open Access article distributed under the terms of the Creative Commons Attribution License, which permits unrestricted use, distribution, and reproduction in any medium, provided the original work is properly cited. 
regulation as we are talking about here in the State of California. But that is up to you, not up to me.

Back to Jeff Sessions, I will have to admit, I talked to him yesterday on a number of subjects. This was one of them. And we have agreed that we are going to have a meeting where we will look in-depth at this issue, and you can rest assured that I learned my lessons about communications from Ronald Reagan, the Great Communicator, and I will put all of those to work to try to expand the realm of freedom for you to live your lives and those adults who want to use cannabis to go right ahead and use it.

I will do everything I can in that discussion with Jeff to push freedom for us, and I will do my best. I cannot tell you what will happen, but I can only predict this. If Jeff Sessions goes the wrong way and convinces the President to reverse his position in the campaignremember, the President specifically said in the campaign, "Medical marijuana should be legal, and adult use should be left up to the states." He said that several times. Now, if Jeff convinces the President to renege on that-I am sorry-but I will tell you this much: I will tell him that I have no doubt that it will go to the courts, and the 9th Circuit Court of Appeals has already verified our position on this, and we do not expect other judges to find fault with that decision. So it would be a huge waste of his time and money, and why would he do that? So I will make the case. We will see what happens.

Mr. Kazan: Thank you for that. Dr. Piomelli, you read an e-mail that pretty much took the air out of the room. Everybody just gasped at getting such an email. The e-mail was from the father of a girl diagnosed with autism. The father wrote that he "would walk through fire to find her a cure." So, let us say one of us received that question-perhaps we have a relative who is dying of cancer or is going through chemotherapy, and they ask us, "What do you know? Should I try cannabis, or should I try some more conventional medicine?" What would your advice be?

Dr. Daniele Piomelli: It is the advice I give to the many people who ask me the same question in their e-mails. I say, "Go to your physician, speak to her or him, and explain to your doctor why you believe that cannabis could be useful for you."

When people ask me that question, I also try to share some data with them. So, for example, if it is a cancer patient suffering from pain, then I send them scientific articles, and I say, "Bring this with you when you see your physician. This is the Journal of the American Medical Association. It is not the Journal of Psychedelic Studies. It is something very serious, and you have to take it seriously." That is all I can do as a basic scientist.

Mr. Kazan: Thank you. So, Lori, you are out there drafting regulations. I know you get lots of comments, and I appreciate that you are here. And I know you travel around the State and put yourself in the firing line, and I sincerely appreciate that. What areas of the regulations are you struggling with?

Lori Ajax: Well, I will tell you, probably the biggest challenges for us were the laboratory regulations. There was both the Adult Use of Marijuana Act and the Medical Cannabis Regulation and Safety Act. The big thing about the cannabis testing was making sure we are testing for pesticides and [meeting regulated] levels of pesticides. So that was probably the biggest challenge.

For me, I was used to doing regulations at my previous agency. But actually, coming up with what we were going to require on an application sometimes can be challenging-what we are going to require? Who is going to be in ownership? Who qualifies as owners?

That was a big question in our preregulation-who is going to be background checked and fingerprinted? And when you see our regulations, you will see we have really taken the approach of aligning them with Proposition 64, the California Marijuana Legalization Initiative. So we are looking at a $20 \%$ aggregate ownership and whatnot, and not having spouses having to be background checked, but having to be disclosed.

So there was a lot of back-and-forth, because we had different sides. Some people wanted more background checks, including employee background checks. There were two different sides on this issue. So [in the final regulation], there are not employee background checks. We really tried to strike a balance.

Mr. Kazan: Thank you. Dana, so what is your advice to people in the business, thinking about entering the business, growing a few plants at home or if I put out something and said, "You should invest with me." What advice would you give those people today, in May of 2017?

Mr. Rohrabacher: The issue has not been definitely settled yet. There are entrepreneurs who are putting 
money into the cannabis business, and especially the medical dispensary business, and they are taking a great risk. There are profits that should come from risks. It is as simple as that. This is a way the free enterprise system works.

And I would hope that no one here begrudges them. Once it becomes legal in this State, and if we manage to secure this arena from federal intervention, I hope no one here begrudges these people the right to make a profit. And I know this is the Republican part of my personality coming out here, but you have many people right now who are taking great risks to get medical cannabis to people who need it.

And yes, it is not certain yet. Not only Jeff Sessions, but who knows? I do not have to tell you folks, but during [the Obama Administration], and now even with Jerry Brown, I have not gotten the cooperation from the Democrats' side that I thought I was going to get.

The Attorney General's office under Obama was not supportive of the efforts that I was making. We made them despite what was going on with the President and the Attorney General then. And of course, Jerry Brown has not stepped up to the plate, either.

So you do not have it settled yet. And if you folks are going to move forward, remember what I just said-the future is not charted. We will make the future. That is the great thing about this country.

Freedom belongs to the activists, and I would hope that we all know that we have to be very active with our elected officials, and by doing that we will protect our freedom to consume, but also, just as important, the right of people investing now to make a profit in providing us the cannabis that people want to consume for their medical reasons.

Mr. Kazan: Dr. Piomelli, you have mentioned addiction as a risk factor with cannabis. There is a lot of talk that I am hearing, this nascent movement of "plant over pills," and we probably have a number of people here that have read about cannabis who are thinking, "Maybe I might try some." Can you expand on addiction and cannabis?

Dr. Piomelli: Yes, that is a very, very important question, Kyle. So let me first start off by stating what is addiction in the medical dictionary-it is a behavior that we pursue despite knowing that it hurts us. That is addiction.

So addiction is not dependence. You can become dependent to a number of different things, and as you be- came dependent, you can also regain full control. It is a complex process, but it can be done. Addiction is different. Addiction is a disease of the brain. It is not a problem of will. It is a disease. It is a chronic disease of the brain.

Now, does cannabis cause addiction? When we think about addiction in the terms I just shared with you, the first thing we think about is opiates, crack cocaine, and alcohol. Those are things that cause devastating forms of addiction we are familiar with, even from a filmic standpoint. We remember the movies, right? And how people in the movies with addiction behave. And we think, "Well, cannabis does not do that." And it is true, cannabis does not do that.

The type of addiction that cannabis causes-and now I think all specialists agree, who have no axe to grind, that cannabis does cause addiction. The type of addiction cannabis causes is of a different type. It is milder, it is harder to get, but it is there.

So $8 \%$ of the people who use it eventually can become addicted. Eight percent does not seem a big number if you compare it with the $45 \%$ that you have with nicotine or the $35-40 \%$ you have with cocaine. It seems like a small number. But if many people use it, even such small percentage will translate into many people.

So I think we need to be cognizant of this and ask ourselves when we talk about medical cannabisbecause that is my main concern-what are we comparing cannabis with?

I believe that chronic pain is one condition that offers the greatest promise for cannabis. And of course, the big comparator in this area is the opioids. And I do not think it needs any introduction to anybody that opioids, although very very effective, are extremely addictive drugs. And there is no question that if we compare cannabis with the opioids, the addictive properties of cannabis are much milder than those of opioids. These are facts.

But then there are many questions, and we need to answer them. Let me point to one in particular. If we combine cannabis and opiates, what happens? That is something we need to understand, because our youth are going to do that, and also our patients are going to do that.

The answer is we do not really know what happens in the long term. We know what happens in the short term. In the short term, if you combine a small dose of an opiate and a small dose of cannabis, you get a lot of painkilling effect. In medical terminology, that is called a synergism with potentiation. But the 
problem is, in the long run, are we enhancing the possibility of getting an addiction to either drug, or are we decreasing it? We need more research on this.

Mr. Kazan: I have to tell you, Daniele, there is a lack of scientific perspective out there, so it is nice that you are willing to speak up like this.

Lori, last question is for you. From people in the cannabis business, I hear many questions about banking. How do we do financing in this field? How do we use credit cards? It may be a tad out of your scope, but I am curious because everything cannabis right now is sort of under your purview. Any comments on banking?

Ms. Ajax: Yes, banking, that is a really tough issue. If any of you watched our budget hearing yesterday, that was a big question. How are all these state agencies going to accept cash, especially if we cannot bank cannabis? And so a lot of time was spent on talking about that: the Board of Equalization, the Bureau, everybody that you are going to have to be bringing cash.

And I think we are preparing for that. Our facilities are preparing to make sure we have a facility that can take cash. But is that really the answer? Probably not the best answer.

Right now, John Chiang, California State Treasurer, has a Banking Cannabis Working Group and I serve as a member on that committee. We are trying to look for solutions. Is there a solution for California? And looking to having a coordinated approach with all the different agencies and the local agencies, and we also have the Cannabis Association represented on this board.
Likely, we are not going to find a solution by January 1, 2018. I think there has to be something happening at the federal level to make it easier for people to bank cannabis. In the meantime, all of us are going to have an online system that can take credit cards, which can take debit cards. We are going to take all forms of payment. We have not figured out Bitcoin yet, but everything else we will take.

So I think that is ongoing, and that is not just the Bureau, that is everybody. That is the industry. That is the state agencies, the federal government. And I think at some point we all need to find the solution together, and I think California coming on board with the legalized market, I am hoping there will be some movement on that.

I will tell you, from my point of view, I realize the issues dealing with cash - the public safety issues. This is a highly regulated product and then you are going to still be using cash? It is very difficult as a regulator to follow the cash. So I think all of us want to find a solution to this.

Mr. Kazan: Thank you. I will tell you, the grow facility for the cannabis field is supposed to gross, when it is all really going, $\mathbf{\$ 3 0}$ million per year. And if state tax were $13 \%$, you can imagine, it is like Scarface or something, with big barrels of cash. So it is a proposition that demands a solution. Thank you all for participating today.

Cite this article as: Kazan K, Piomelli D, Rohrabacher D, Ajax L (2017) Expert panel on understanding cannabis: medicine, society, government, Cannabis and Cannabinoid Research 2:1, 247-251, DOI: 10.1089/ can.2017.29010.kka.
Cannabis and Cannabinoid Research
- Immediate, unrestricted online access

- Rigorous peer review

- Compliance with open access mandates

- Authors retain copyright

- Highly indexed

- Targeted email marketing 
This Expert Panel Discussion was sponsored by

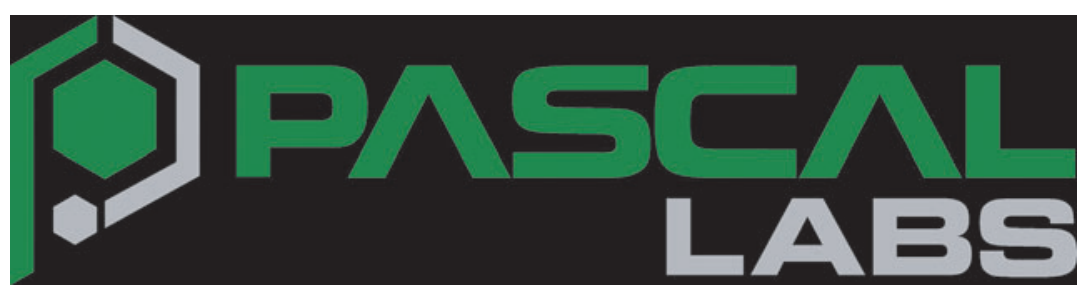

